\title{
ESTIMATING THE IMPACT OF URBAN EXPANSION ON LAND SUBSIDENCE USING TIME SERIES OF DMSP NIGHT-TIME LIGHT SATELLITE IMAGERY
}

\author{
Shuai Jiao ${ }^{1,2,3}$, Jie $\mathrm{Yu}^{1,2,3^{*}}$, Yanbing Wang ${ }^{1,2,3}$, Lin Zhu ${ }^{1,2,3}$, Qi Zhou ${ }^{4}$ \\ ${ }^{1}$ College of Resource Environment and Tourism, Capital Normal University, Beijing 100048, China - (jfire2009@163.com, \\ yuj2015@cnu.edu.cn, wybcnu@sina.com, hi-zhulin@163.com) \\ ${ }^{2}$ State Key Laboratory Incubation Base of Urban Environmental Processes and Digital Simulation, Beijing 100048, China \\ ${ }^{3}$ Beijing Key Laboratory of Resource Environment and Geographic Information System, Beijing 100048, China \\ ${ }^{4}$ National Geomatics Center of China, Beijing 100830, China - (zhouqi@ngcc.cn)
}

Commission III, WG III/3

KEY WORDS: land subsidence, urban expansion, DMSP/OLS NTL, PSInSAR

\begin{abstract}
:
In recent decades, urbanization has resulted a massive increase in the amount of infrastructure especially large buildings in large cities worldwide. There has been a noticeable expansion of entire cities both horizontally and vertically. One of the common consequences of urban expansion is the increase of ground loads, which may trigger land subsidence and can be a potential threat of public safety. Monitoring trends of urban expansion and land subsidence using remote sensing technology is needed to ensure safety along with urban planning and development. The Defense Meteorological Satellite Program Operational Line scan System (DMSP/OLS) NightTime Light (NTL) images have been used to study urbanization at a regional scale, proving the capability of recognizing urban expansion patterns. In the current study, a normalized illuminated urban area dome volume (IUADV) based on inter-calibrated DMSP/OLS NTL images is shown as a practical approach for estimating urban expansion of Beijing at a single period in time and over subsequent years. To estimate the impact of urban expansion on land subsidence, IUADV was correlated with land subsidence rates obtained using the Stanford Method for Persistent Scatterers (StaMPS) approach within the Persistent Scatterers InSAR (PSInSAR) methodology. Moderate correlations are observed between the urban expansion based on the DMSP/OLS NTL images and land subsidence. The correlation coefficients between the urban expansion of each year and land subsidence tends to gradually decrease over time (Coefficient of determination $\mathrm{R}=0.80-0.64$ from year 2005 to year 2010), while the urban expansion of two sequential years exhibit an opposite trend $(\mathrm{R}=0.29-0.57$ from year 2005 to year 2010) except for the two sequential years between 2007 and $2008(\mathrm{R}=0.14)$.
\end{abstract}

\section{INTRODUCTION}

Land subsidence is the process of lowering the ground surface elevation due to natural or human-induced impacts. Damage caused by land subsidence can be fatal and may cause problems such as changes in elevation and slope of streams and drains, damage to buildings, bridges and infrastructure (Amelung et al.,1999). A number of studies have shown that the excessive exploitation of groundwater is one of the main causes of the land subsidence (Pratt and Johnson 1926; Lewis and Schrefler 1978; Zhao et al., 2016). Overuse of aquifers in urban areas is amplified by urban population growth and development. Meanwhile, with the process of urbanization, high building density, large building footprints, and building volumes are found to have major impacts (Yan, 2002; Jie et al., 2007; Chen et al., 2015; Jiao et al., 2017). Land subsidence as a result of the load caused by urban expansion is becoming a critical issue in many major cities such as Beijing in China, influencing the urban security and further development of the city (Abidin et al., 2001; Gong, 2002; Chen et al., 2015).

Remote sensing technologies have been extensively used in regional hydrological and geo-mechanical models to quantify the relationship between urban expansion and land subsidence. Following the development of Synthetic Aperture Radar (SAR) remote sensing technology in recent years, SAR interferometry (InSAR) has developed into a potential tool for monitoring land subsidence (Graham, 1974). In particular, the Permanent Scatterers InSAR (PSInSAR) technique is praised as a potentially unique tool for monitoring fine land deformation over large areas (Ferretti et al., 2001). Permanent Scatterers (PS) are identified from long temporal series of interferometric SAR images. PS points are stable radar targets, which have time stable amplitude and phase in all exploited SAR images (Lesniak and Porzycka 2009). The advantages of PSInSAR are that it reduces space and time decoherence, impairs the influence of atmospheric delay and obtains accurate sequence deformation of PS to improve the capacity of monitoring ground subsidence (Ferretti et al.,2001; Colesanti et al.,2003). In 2004, Hooper et al. developed StaMPS (Stanford Method for Persistent Scatterers), as an extension of the PSInSAR technique, to identify the point targets with low scattering intensity and phase stability, increasing the spatial density of the identification points. StaMPS has proven to be effective in monitoring land subsidence in the Beijing area using high resolution images to recognize miniscule ground deformation (Chen et al.,2015; Zhu et al.,2015). While these studies used remote sensing, and PSInSAR technology, in particular, to monitor the relationships between lands subsidence and a single urban property such as building load pressure (Tang et al., 2008; Cui et al., 2010), or building volume (Jiao et al., 2017), there is no study that uses remote sensing to observe the impact of urban expansion as a whole, where the load caused by urban expansion on land subsidence is explored.

The Nigh-Time light (NTL) satellite images collected by the Defense Meteorological Satellite Program (DMSP) Operational Linescan System (OLS) sensor has become widely used to study the pattern of human activity and urban development. In 1978,

\footnotetext{
* Corresponding author
} 
Croft (1978) first identified the potential of NTL data to observe human activities. Since then, various studies have demonstrated strong relationships between NTL data and key socioeconomic variables such as urban population estimates (Elvidge et al., 1997a; Sutton et al., 2001; Amaral et al., 2006; Balk et al., 2006), population density (Sutton et al., 2003; Zhuo et al., 2009), economic activity (Doll et al., 2006), energy use (Doll et al., 2000; Elvidge et al., 1997b), impervious surfaces (Elvidge et al., 2007), and sub-national estimates of gross domestic product (GDP) (Sutton et al., 2007).

In a recent study, DMSP/OLS NTL data was successfully used to estimate urban growth. Lo (2002) extracted surface area and volume of city lights from DMSP/OLS NTL and demonstrated the strong relationship between the volume of city lights and urban indicators, including urban population, gross domestic product GDP), built-up areas, and electric power consumption (EPC) in large city of China such as Beijing, Shanghai and Tianjin. Chen et al. (2003) established a complex light index, which also included the four variables, from DMSP/OLS NTL to estimate the urbanization of China. Ma et al. (2012) verified the capability of DMSP/OLS NTL for estimating long-term trends of four urbanization variables: urban population, gross domestic product (GDP), built-up areas, and electric power consumption (EPC) for prefectural-level cities. The mentioned studies considered that DMSP/OLS NTL could be used to illustrate the morphology of a large city by the four urban indicators (urban population, GDP, built-up areas and EPC) estimation models.

In this paper we combine the capability of DMSP/OLS NTL with the StaMPS method to examine the impact of the urbanization status derived from DMSP/OLS NTL on land subsidence in Beijing, China. Similarly to Lo (2002), we calculated normalized illuminated urban area (IUA) dome volume from DMSP/OLS NTL to illustrate the urban expansion of Tongzhou and Chaoyang Districts, two adjacent areas in Beijing in the period from 2005 to 2010 . The urban expansions are compared with land subsidence measurements generated from Envisat ASAR temporal images using the StaMPS method.

\section{METHODS}

The overall method in the current study included an intercalibration method to adjust time-series DMSP/OLS NTL images from 2005 to 2010, which were then used to estimate the urban expansion. For the same period, 39 ASAR image were used in the StaMPS method to estimate the land subsidence rate of the study area. The data was then compared as explained in the following sections.

\subsection{Urban expansion estimation by DMSP/OLS}

Because of the differences in radiometric performance, lack of onboard radiometric calibration, and sensor degradation over time, data from different OLS instruments require intercalibration before they can be used to assess lighting changes over time. To improve the consistency and comparability of the NTL temporal data, we adapted an empirical procedure named second order regression model, which was validated by Elvidge in 2009 (Elvidge et al., 2009). Since multiple images were not available from the same instrument, we selected images from satellite F16 acquired from 2005 to 2009 and one image from satellite F18 acquired in 2010. The inter-calibration of the datasets was conducted by using second order polynomial regression (Eq. 1) (Yi et al., 2014). The calibrated DNs were calculated as:

$$
D N_{\text {calibrated }}=a \times D N^{2}+b \times D N+c
$$

where $\mathrm{DN}$ is a digital number value of a pixel, and $\mathrm{DN}_{\text {calibrated }}$ is the inter-calibrated DN. The model coefficients $\mathrm{a}, \mathrm{b}$ and $\mathrm{c}$ were used as proposed by Yi (Yi et al., 2014) (Table 1).

\begin{tabular}{llllll}
\hline Satellite & Year & $\mathrm{a}$ & $\mathrm{b}$ & $\mathrm{c}$ & $\mathrm{R}^{2}$ \\
\hline F15 & 2005 & 0.0071 & 0.4805 & 0.6281 & 0.955 \\
F15 & 2006 & 0.0057 & 0.6042 & 0.2504 & 0.979 \\
F15 & 2007 & 0.0049 & 0.6308 & 0.1775 & 0.983 \\
F16 & 2005 & 0.0073 & 0.4648 & 0.8615 & 0.963 \\
F16 & 2006 & 0.0029 & 0.7822 & 0.2173 & 0.976 \\
F16 & 2007 & 1.0000 & 0.0000 & 0.0000 & 1.000 \\
F16 & 2008 & -0.0003 & 1.0258 & -0.0870 & 0.983 \\
F16 & 2009 & -0.0017 & 1.0388 & 0.0057 & 0.897 \\
F18 & 2010 & 0.0121 & 0.1277 & 0.0121 & 0.848 \\
\hline
\end{tabular}

Table 1. Inter-calibration coefficient used in the current study for the period between 2005 and 2010 (Yi et al., 2014)

After inter-calibration, illuminated urban area (IUA) dome is calculated as (Eq. 2):

$$
I U A=D N_{\text {calibrated }} \times S
$$

where $D N_{\text {calibrated }}$ donates the inter-calibrated $\mathrm{DN}$ of DMSP/OLS and $\mathrm{S}$ donates the area of the grid. After normalization, normalized IUA dome volume (NIUADV) is obtained to illustrate the urban expansion.

\subsection{Land subsidence monitoring by Stanford Method for Persistent Scatterers (StaMPS)}

To obtain the land subsidence rate from 2005 to 2010, StaMPS (Hooper et al., 2004), was applied in our study to identify phase components, using amplitude discrete features and characteristics of the interferometric phase spatial correlation for PS recognition algorithm to identify permanent scatterers (PSs). Without any prior knowledge of the deformation rate, we attempted to overcome the problems due to time decoherence, improving the number of available interferograms and time resolution (Chen et al., 2015). The StaMPS is conducted as (Eq. 3):

$$
\emptyset_{p}^{i, k}=\emptyset_{S}^{i, k}+\emptyset_{B}^{i, k}+\emptyset_{T}^{i, k}+\emptyset_{N}^{i, k}
$$

where $\emptyset_{p}^{i, k}$ donates the differential phase of interferometry obtained by $\mathrm{i}$ image and $\mathrm{k}$ image; $\emptyset_{S}^{i, k}$ donates the spatial correlation phase composed of atmospheric phase, orbit error, spatial correlation DEM and surface deformation; $\emptyset_{B}^{i, k}$ donates the component correlated to the perpendicular baseline; $\emptyset_{T}^{i, k}$ donates component of temporal phase, consisted of nonspatially correlated surface deformation and atmospheric phase caused by seasonal variations; $\emptyset_{N}^{i, k}$ donates random noise.

To validate the precision of StaMPS result, several PSs within a range of $200 \mathrm{~m}$ were selected to calculate the average value of 
land subsidence which is then compared to land subsidence of bench mark with the known values. The land subsidence rate result of PSs was interpolated to raster image using Kriging method in Universal Transverse Mercator projection, UTM, Zone 50.

\subsection{Relationship between urban expansion and land subsidence evaluation}

Spearman's rank correlation coefficient is a nonparametric measure of rank correlation, which is used to assess the relationship between two variables by a monotonic function.

To evaluate the relationship between urban expansion and land subsidence, we chose to calculate the Spearman correlation coefficient. After the geo-registration (UTM 50), time-series NIUADVs and land subsidence rates are extracted to the same range in ArcMAP. The Spearman correlation coefficient between time-series NIUADVs and land subsidence rate can be calculated in Matlab for the analysis of the impact of urban expansion on land subsidence.

\section{STUDY AREA AND DATASETS}

\subsection{Study area}

Beijing is the capital of China and one of the most populous cities in the world with a population of over 20 million. The city occupies $16807.8 \mathrm{~km}^{2}$ in area and it is bordered by mountains to the northwest and by the sector plain southeast of the city. Beijing is affected by a continental monsoon climate, with an average annual precipitation of $588 \mathrm{~mm} /$ year (1956-2002) and with $80 \%$ of the annual accumulation occurring between mid-June and September. Beijing's plain is composed of water-bearing alluvial-pluvial and river channel deposits overlying bedrock. Tertiary and older sedimentary and volcanic rock units underlie Quaternary sediments and form the lateral and basal boundaries of the aquifer system. Groundwater is the main water source for the population of Beijing. The city is known for water shortages as ground water extraction counts for $2 / 3$ of total water supply (Zhu et al., 2015). Since 1990, relatively stable pumping rates have been maintained at about $2.5 \times 109 \mathrm{~m} 3 /$ year (Zhang et al., 2014).

With urbanization, high-rise buildings have become urban landmarks and the subway system has become the conventional mode of transportation. In recent two decades, the development of central cities (Xicheng and Dongcheng district) remains stable, while eastern cities such as Shunyi and Tongzhou district have been developing exponentially. At the beginning of the $21 \mathrm{st}$ century, Chaoyang became the economic center of Beijing. Especially during the preparation for the 2008 Olympic Games, the district became known for its excessive landscape transformation. During the same period the Tongzhou district became the "Sleeping City", where the increase of residential development was evident, especially after 2006.

According to previous studies, land subsidence in the middle of Beijing (Xicheng and Dongcheng District) has remained stable (Chen et al., 2015; Zhang et al., 2014), while there is relatively serious land subsidence in east Beijing. Before 2007, a serious land subsidence region was defined in the southeast region of Beijing, where the accumulative ground subsidence was found to be as high as $722 \mathrm{~mm}$, affecting the common life and the building security. Monitoring and analysis of the land subsidence trend in this area has become an important issue for Beijing. In this study, we chose the southeast region of Beijing (Figure 1), including two districts (Chaoyang and Tongzhou district), as study sites to evaluate the impact of urban expansion on land subsidence.

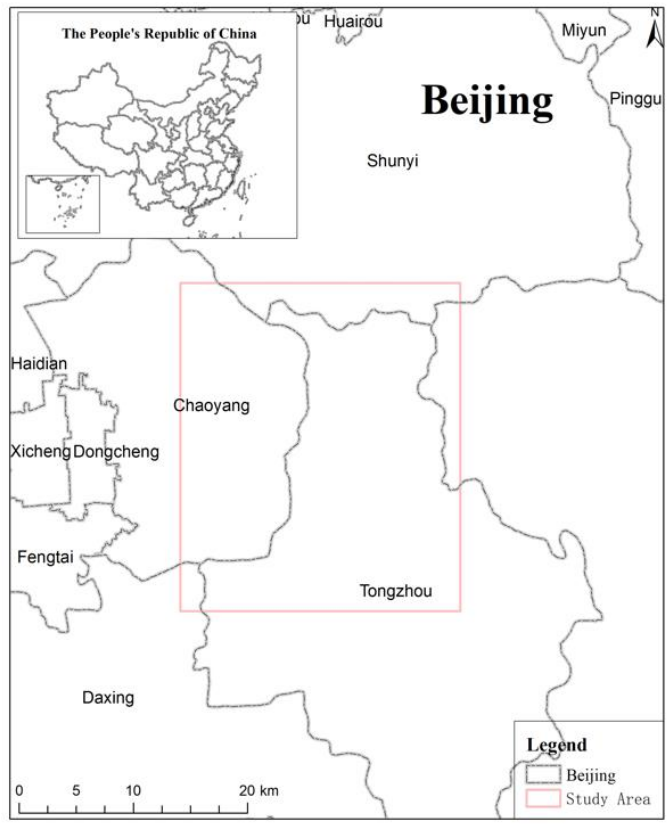

Figure 1. Study area

\subsection{Data}

3.2.1 Multi-temporal dataset of DMSP/OLS night time light: The Operational Linescan System (OLS) was developed under the Defense Meteorological Satellite Program (DMSP). The DMSP/OLS instrument was initially designed to observe clouds illuminated by moonlight or the Night-Time Light (NTL) data (Elvidge et al., 1997a). DMSP/OLS has a wide orbital swath scanning the land surface as wide as $3000 \mathrm{~km}$ in one pass. The data acquisition by DMSP /OLS started in 1972 from six satellites in the DMSP system: F10 (1992-1994), F12 (19941999), F14 (1997-2003), F15 (2000-2007), F16 (2004-2009) and F18 (2010-Present). The DMSP stable lights product provides annual composites of NTL images from a broad spectral band $(0.4-1.1 \mu \mathrm{m})$ which are filtered to remove the effects of moonlight, stray light, clouds, and ephemeral light sources such as fires and gas flares. The digital numbers (DN) range between 0 and 63 , where 0 corresponds to no light or missing data, and the range between 1-63, which corresponds to the range between the lowest detectable and saturation radiance (Ma et al., 2012).

In the current study the Version 4 DMSP/OLS stable lights product developed for the period between 2005 and 2010 (F16: 2005-2009 and F18: 2010) was used for the higher coefficient than the other alternative F15 2005-2007 (Table 2). 
3.2.2 Envisat ASAR: The remote sensing data used to observe land subsidence rate included 39 Advanced Synthetic Aperture Radar (ASAR) satellite images. ASAR is an active radar satellite sensor launched by European Space Agency (ESA) in 2002 (Holah et al., 2005). The images had both the ground and azimuth range resolutions of $30.0 \mathrm{~m}$. In the current study, we used 39 ASAR images for the period between 2005 and 2010. The height of the satellite acquiring radar data according to the master image was defined as $0 \mathrm{~m}$. The image acquired on December 3, 2008 was chosen to be the master image. Another 38 images were co-registered to the master image at the subpixel level. The spatial-temporal baseline distribution is shown in Figure 2. The spatial baselines are unevenly distributed in elevation direction and the maximum spatial baseline span is less than 700 meters (Figure 2). The relative height of the satellite acquiring radar data is shown in Table 2.

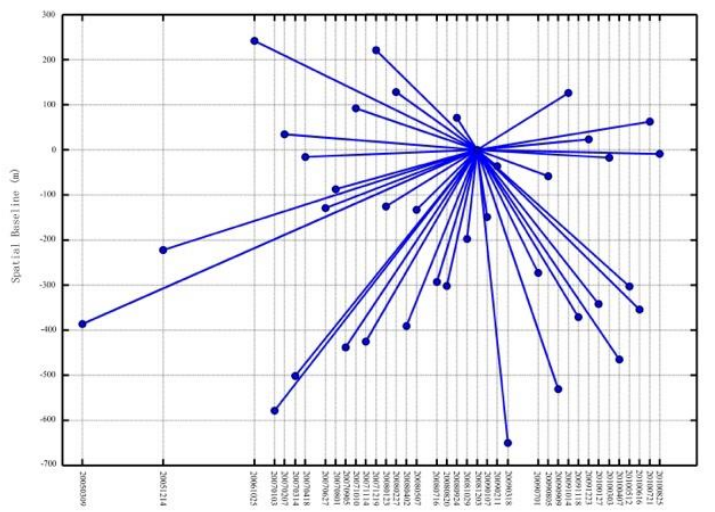

Figure 2. Spatial-temporal baseline of Envisat ASAR

\begin{tabular}{cccccc}
\hline Data & Baseline & Data & Baseline & Data & Baseline \\
\hline 20050309 & -386.37 & 20071219 & 221.11 & 20090701 & -272.72 \\
20051214 & -222.23 & 20080123 & -125.55 & 20090805 & -58.29 \\
20060816 & -967.59 & 20080227 & 128.17 & 20090909 & -530.69 \\
20061025 & 241.68 & 20080402 & -390.90 & 20091014 & 126.18 \\
20070103 & -578.57 & 20080507 & -132.92 & 20091118 & -370.94 \\
20070207 & 34.56 & 20080716 & -292.92 & 20091223 & 23.34 \\
20070314 & -501.40 & 20080820 & -302.04 & 20100127 & -341.96 \\
20070418 & -15.73 & 20080924 & 71.06 & 20100303 & -17.38 \\
20070627 & -129.27 & 20081029 & -197.73 & 20100407 & -464.80 \\
20070801 & -87.26 & 20081203 & 0.00 & 20100512 & -303.12 \\
20070905 & -438.03 & 20090107 & -148.82 & 20100616 & -354.13 \\
20071010 & 92.21 & 20090211 & -36.17 & 20100721 & 62.59 \\
20071114 & -425.27 & 20090318 & -650.00 & 20100825 & -8.97 \\
\hline
\end{tabular}

Table 2. Height of the satellite acquiring radar data. Note: Baseline represents the distance between master image and slave image

\section{RESULT}

\subsection{Land subsidence results via StaMPS}

The land subsidence based on the StaMPS method is more apparent in the east of Chaoyang and the northwest of Tongzhou where it ranges from 0 to $-110 \mathrm{~mm} / \mathrm{yr}$ (Figure 3). The validation process suggests that the land subsidence rate values at the chosen bench marks and the average land subsidence values of PSs within 200 meters around each bench mark do not differ considerably (1.81-3.97 mm/yr) and the trends follow each other (Table 3). The average difference value over the points is 3.08 of $\mathrm{mm} / \mathrm{yr}$. The errors may be introduced by the algorithm as the differences are relatively consistent over all points.

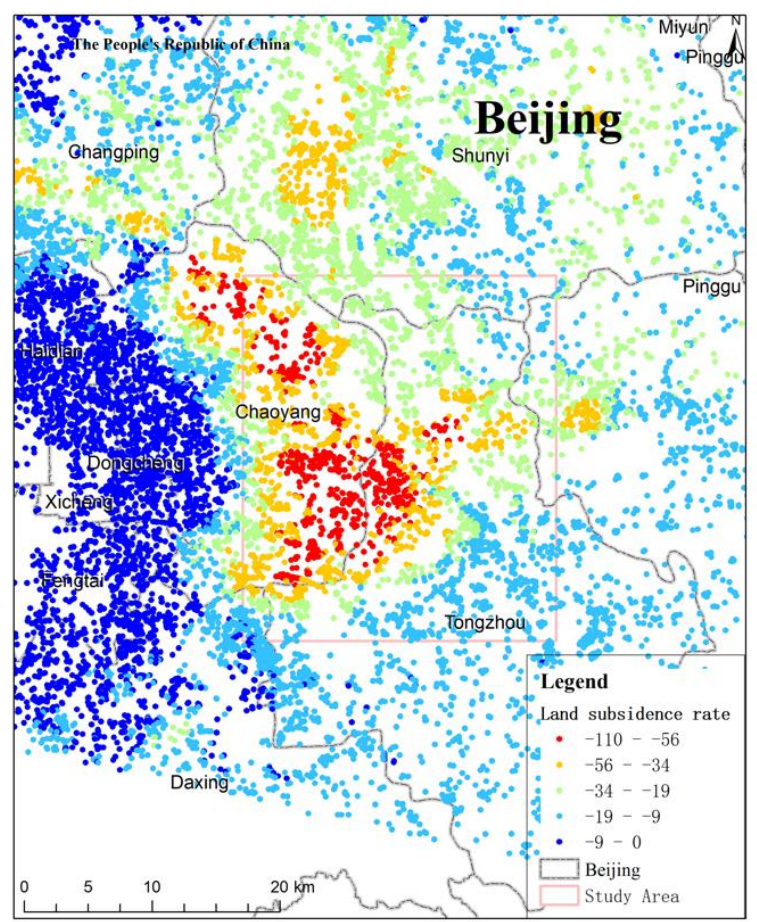

Figure 3. Land subsidence map obtained by StaMPS

\begin{tabular}{cccc}
\hline $\begin{array}{l}\text { Bench- } \\
\text { mark ID }\end{array}$ & $\begin{array}{l}\text { Bench mark } \\
\text { deformation } \\
(\mathrm{mm} / \mathrm{yr})\end{array}$ & $\begin{array}{l}\text { Average value of } \\
\text { PSs around } \\
\text { bench mark } \\
(\mathrm{mm} / \mathrm{yr})\end{array}$ & $\begin{array}{l}\text { Absolute } \\
\text { difference } \\
(\mathrm{mm} / \mathrm{yr})\end{array}$ \\
\hline BM1 & -1.25 & -3.34 & 2.09 \\
BM2 & -0.50 & -2.31 & 1.81 \\
BM3 & -1.25 & -4.83 & 3.58 \\
BM4 & -6.25 & -8.95 & 2.7 \\
BM5 & -12.13 & -9.11 & 3.02 \\
BM6 & -52.75 & -56.72 & 3.97 \\
BM7 & -30.50 & -26.55 & 3.95 \\
BM8 & -33.25 & -29.75 & 3.50 \\
\hline
\end{tabular}

Table 3. The difference of land subsidence between benchmarks and PSs 


\subsection{Validation of the relationship between DMSP/OLS NTL and urban expansion}

To quantify the magnitude of NTL images from the intercalibrated DMSP/OLS dataset, weighted light area (WLA) is defined as the weighted sum of areas of lit pixels multiplied by the normalized DN (Ma et al., 2012).Therefore, the WLA was normalized to the range 0 to 1 to estimate the response of DMSP/OLS NTL images to urbanization variables (GDP, population, EPC and Built-up area).The linear regression models applied to the WLA and four urbanization variables are shown in Figure 4.

All four variables demonstrate relatively strong relationships with WLA. $\mathrm{R}^{2}=0.78, \mathrm{R}^{2}=0.78, \mathrm{R}^{2}=0.82, \mathrm{R}^{2}=0.69$ for $\mathrm{GDP}$, population, EPC, and build-up area, respectively, and all four regression trends are significant $(\mathrm{p}=0.05)$.
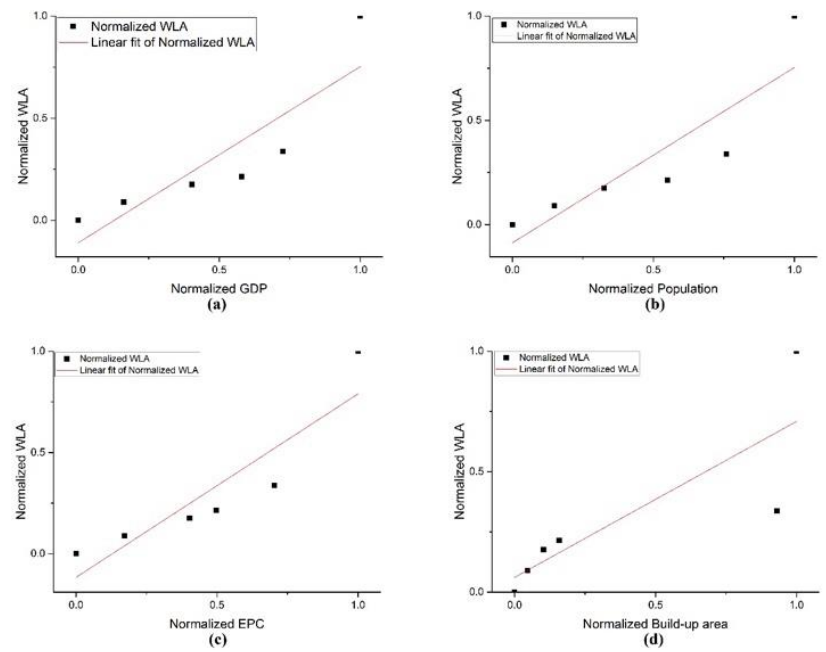

Figure 4. Linear response of DMSP/OLS NTL signals shown as normalized WLA and a) normalized GPD; b) normalized population; c) normalized EPC; d) normalized built-up area

After normalization, the four urbanization variables and WLA are plot over the years to explore their trends (Figure 5). The four variables as well as WLA increases over time. GDP, population and EPC tend to grow gradually at a stable rate while the builtup area and WLA first increase much slower and then suddenly increases significantly in 2008 and 2009, respectively.

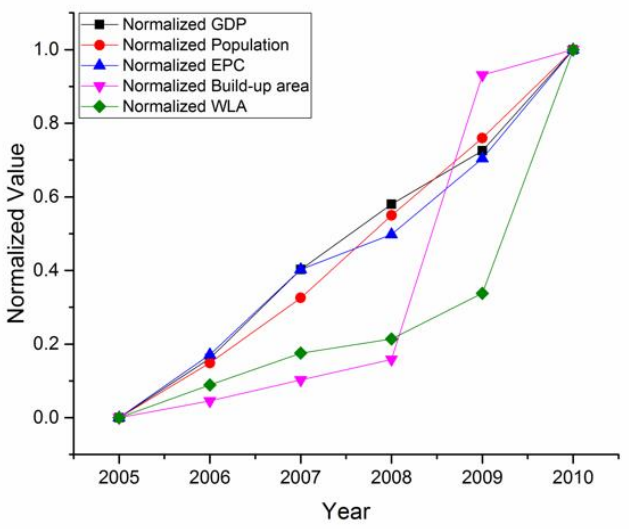

Figure 5. The trends of normalized urbanization variables and WLA

The difference in values of the normalized urbanization variables and WLA between two subsequent years, calculated to examine the urban expansion of two sequential years and its response to DMSP/OLS NTL images, are shown in Figure 6. The largest differences are observed for the built-up areas between 2008 and 2009 followed by the WLA difference between 2009 and 2010. The difference in values for the built-up areas between 2008 and 2009 is almost seven times greater than for any other years. A slight population increase and largest decrease in EPC are observed between year 2007 and 2008. A decrease in GDP is observed from 2006-2007 to 2008-2009.

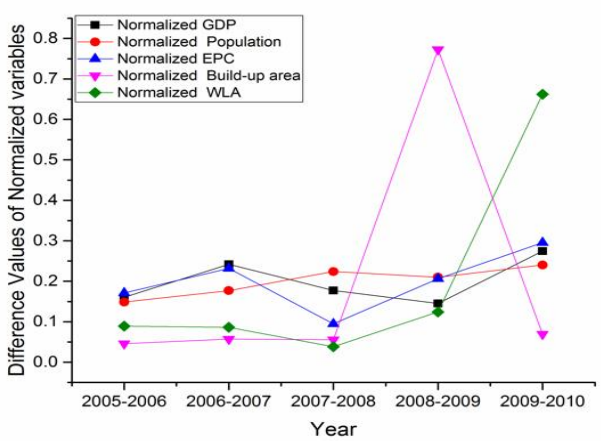

Figure 6. The difference in values of the normalized urbanization variables and WLA between two subsequent years

\subsection{Relationship between land subsidence and urban expansion}

To explore the possible response of DMSP/OLS NTL images to land subsidence, we adapted Kriging interpolation method to the land subsidence rate of PSs in order to obtain land subsidence grid data.

The Spearman's rank correlation coefficients between the land subsidence rate and time series of the DMSP/OLS NTL images are gradually reducing with time. (From 0.80 for 2005 to 0.64 for 2010, Table 4). To exam the response of the change of DMSP/OLS NTL images in two subsequent years to land subsidence. Five figures were drawn by subtracting two DMSP/OLS NTL images in sequential years. The Spearman's rank correlation coefficients between the land subsidence rate and time-series of DMSP/OLS NTL images are gradually increasing from 0.28 for 2005 to 0.57 for 2010, with the exception of the pre-Olympic Game period between 2007 and 2008 when the correlation is low $(\mathrm{R}=0.14)$ (Table 5) .

\begin{tabular}{ccccccc}
\hline & 2005 & 2006 & 2007 & 2008 & 2009 & 2010 \\
\hline $\begin{array}{l}\text { Correlation } \\
\text { Coefficient }\end{array}$ & 0.80 & 0.78 & 0.73 & 0.72 & 0.70 & 0.64 \\
\hline Table 4. The correlation coefficient of land subsidence and \\
DMSP/OLS NTL images
\end{tabular}

Table 5. The correlation coefficient of land subsidence and the difference value of between two DMSP/OLS NTL images of two sequence years 


\section{DISCUSSION}

This study has demonstrated the applicability of DMSP/OLS NTL images for monitoring the status of urban expansion. With that in mind we further explored the relationship between DMSP/OLS NTL images and land subsidence measurements generated using ASAR data. Differently from previous studies where land subsidence is typically related to a single physical property of urban settings extracted from satellite imagery (building height, etc.), in this study several socio-economic urban properties are related to the satellite data showing relatively high correlation between the WLA generated from DMSP/OLS NTL images and all four variables.

The temporal trend (Figure 4) suggest a constant increase of GDP population and EPC over five years. The WLA values follow the trend of the Built-up areas with the one year time lag which may suggest that data on the built-up areas were collected during the construction, before the lights were in use. A sudden urban expansion is observed in 2008 (Figure 4 and 5). At the same time a slight increase in the population rate is observed between 2007 and 2008 .

A relatively strong positive correlation between land subsidence rate and DMSP/OLS NTL images in the period from 2005 to 2010 (Table 4) was observed, which means urban expansion of each single year has an impact on land subsidence, and is in agreement with previous studies (Jie et al., 2007; Tang et al., 2008) where building load and building density was shown to have the long-term impact on land subsidence in the same area. The impact tends to reduce as time goes on. According Jiao's study (Jiao et al., 2017), once the building volume grows large enough, the impact of building load becomes stable.

In the period ranging from 2005 to 2010 , there is a rapid urbanization in Beijing. Especially before 2008, a large number of constructs were built for the Olympic Games held in Beijing in 2008.The increasing correlation coefficients between land subsidence rate and DMSP/OLS NTL image, with the exception of the years between 2007 and 2008 (Table 4 and 5), suggest that the change of urban expansion of two sequential years does have impact on land subsidence and the impact increases overtime.

The low correlation between land subsidence and the change of urban expansion during the period between 2007 and 2008 may be due to lower WLA triggered by the reduced EPC during this period. In Figure 5, WLA showed a similar trend as EPC suggesting the impact or reduced EPC on the NTL brightness in DMSP/OLS imagery. In the period between 2007 and 2008, the difference value of EPC of these two years reach the minimum level of this six years, directly leading the impairment of intense DMSP/OLS NTL brightness and resulting in the low correlation between land subsidence and urban expansion of two sequential years.

Although the results suggest that the DMSP/OLS NTL imagery are correlated with the socio-economic urban variable and that the same data can be used to monitor land subsidence, the current study has many uncertainties and it serves as a basis for further research. More information on data collection, additional variables and a longer time series analysis should be considered to be more conclusive. Some major uncertainties in this study are:

1. Built-up area grew rapidly in 2009 and the growth rate decreased after 2009. The sudden change may have influence on land subsidence, however, this change may not be shown in DMSP/OLS NTL image.
2. We utilized a regular rectangular study area to study the impact of urban expansion on land subsidence, however, there is a common problem in the study of geography, which is the scale effect. In the future study, scale effect should be discussed more to reveal the relationship between urban expansion and land subsidence in details.

\section{CONCLUSION}

This study has demonstrated time-series DMSP/OLS NTL images have a potential to estimate the urban expansion at regional scale (Tongzhou and Chaoyang district, Beijing). The method proposed in this paper considers urban expansion based on the satellite imagery and as such was used to monitor land subsidence derived from ASAR data where the impact of urban expansion on land subsidence was examined.

The findings suggest a relatively high correlation between urban expansion of each single year and land subsidence rate, and the correlation tended to decrease over time, suggesting that urban expansion of each single year did have an impact on land subsidence, however, the influence tends to decrease in subsequent years. Besides, the correlation of differences of every two subsequent years in the period from 2005 to 2010 as land subsidence tends to increase over time, this suggests the increase impact of urban expansion of two sequential years on land subsidence. The change of urban expansion of two sequential years should be given higher priority to ensure building security and maintain common human lifestyle in the city.

\section{ACKNOWLEDGEMENTS}

This work was funded by the National Natural Science Foundation of China (Grant No. 41671417).

\section{REFERENCE}

Abidin, H.Z., Djaja, R., Darmawan, D., Hadi, S., Akbar, A., Rajiyowiryono, H., Sudibyo, Y., Meilano, I., Kasuma, M., Kahar, J., 2001. Land subsidence of Jakarta (Indonesia) and its geodetic monitoring system. Natural Hazards 23(2-3), pp. 365-387.

Amaral, S., Monteiro, A.M., Câmara, G., Quintanilha, J., 2006. DMSP/OLS night-time light imagery for urban population estimates in the Brazilian Amazon. International Journal of Remote Sensing 27(05), pp. 855-870.

Amelung, F., Galloway, D.L., Bell, J.W., Zebker, H.A., Laczniak, R.J., 1999. Sensing the ups and downs of Las Vegas: InSAR reveals structural control of land subsidence and aquifer-system deformation. Geology 27(6), pp. 483-486.

Balk, D., Deichmann, U., Yetman, G., Pozzi, F., Hay, S., Nelson, A., 2006. Determining global population distribution: methods, applications and data. Advances in parasitology 62, pp. 119-156.

Chen, B., Gong, H., Li, X., Lei, K., Ke, Y., Duan, G., Zhou, C., 2015. Spatial correlation between land subsidence and urbanization in Beijing, China. Natural Hazards 75(3), pp. 2637 2652.

Chen, J., Zhuo, L., Shi, P.j., Toshiaki, I., 2003. The study on urbanization process in China based on DMSP/OLS data: Development of a light index for urbanization level estimation. JOURNAL OF REMOTE SENSING-BEIJING- 7(3), pp. 168175. 
Colesanti, C., Ferretti, A., Prati, C., Rocca, F., 2003. Monitoring landslides and tectonic motions with the Permanent Scatterers Technique. Engineering Geology 68(1-2), pp. 3-14.

Croft, T.A., 1978. Nighttime images of the earth from space. Scientific American 239(1), pp. 86-101.

Cui, Z.-D., Tang, Y.-Q., 2010. Land subsidence and pore structure of soils caused by the high-rise building group through centrifuge model test. Engineering Geology 113(1-4), pp. 44-52.

Doll, C.H., Muller, J.-P., Elvidge, C.D., 2000. Night-time imagery as a tool for global mapping of socioeconomic parameters and greenhouse gas emissions. AMBIO: a Journal of the Human Environment 29(3), pp. 157-162.

Doll, C.N., Muller, J.-P., Morley, J.G., 2006. Mapping regional economic activity from night-time light satellite imagery. Ecological Economics 57(1), pp. 75-92.

Elvidge, C.D., Baugh, K.E., Kihn, E.A., Kroehl, H.W., Davis, E.R., 1997a. Mapping city lights with nighttime data from the DMSP Operational Linescan System. Photogrammetric Engineering and Remote Sensing 63(6), pp. 727-734.

Elvidge, C.D., Baugh, K.E., Kihn, E.A., Kroehl, H.W., Davis, E.R., Davis, C.W., 1997b. Relation between satellite observed visible-near infrared emissions, population, economic activity and electric power consumption. International Journal of Remote Sensing 18(6), pp. 1373-1379.

Elvidge, C.D., Imhoff, M.L., Baugh, K.E., Hobson, V.R., Nelson, I., Safran, J., Dietz, J.B., Tuttle, B.T., 2001. Night-time lights of the world: 1994-1995. ISPRS Journal of Photogrammetry and Remote Sensing 56(2), pp. 81-99.

Elvidge, C.D., Tuttle, B.T., Sutton, P.C., Baugh, K.E., Howard, A.T., Milesi, C., Bhaduri, B., Nemani, R., 2007. Global distribution and density of constructed impervious surfaces. Sensors 7(9), pp. 1962-1979.

Elvidge, C.D., Ziskin, D., Baugh, K.E., Tuttle, B.T., Ghosh, T., Pack, D.W., Erwin, E.H., Zhizhin, M., 2009. A fifteen year record of global natural gas flaring derived from satellite data. Energies 2(3), pp. 595-622.

Ferretti, A., Prati, C., Rocca, F., 2001. Permanent scatterers in SAR interferometry. IEEE Transactions on geoscience and remote sensing 39(1), pp. 8-20.

Gong, S.L., 1998. Effects of urban construction on the land subsidence in Shanghai. Chin J Geol Hazard Control 9(2), pp. $108-111$.

Gong, S.L., 2002. The microscopic characteristics of Shanghai soft clay and its effect on soil mass deformation and land subsidence. J Eng Geol 10(4), pp. 378-384.

Graham, L.C., 1974. Synthetic interferometer radar for topographic mapping. Proceedings of the IEEE 62(6), pp. 763768 .

Holah, N., Baghdadi, N., Zribi, M., Bruand, A., King, C., 2005. Potential of ASAR/ENVISAT for the characterization of soil surface parameters over bare agricultural fields. Remote sensing of environment 96(1), pp. 78-86.
Hooper, A., Zebker, H., Segall, P., Kampes, B., 2004. A new method for measuring deformation on volcanoes and other natural terrains using InSAR persistent scatterers. Geophysical research letters $31(23)$.

Jiao, S., Yu, J., Simic Milas, A., Li, X., Liu, L., 2017. Assessing the Impact of Building Volume on Land Subsidence in the Central Business District of Beijing with SAR Tomography. Canadian Journal of Remote Sensing 43(2), pp. 177-193.

Jie, Y., Gao, Y., Li, G., Liu, Y., Sun, T., 2007. Discussion on influence depth of large-scale load in urban construction. Industrial Architecture 37(6), pp. 57-62.

Lesniak, A., Porzycka, S., 2009. Geostatistical computing in PSInSAR data analysis, International Conference on Computational Science. Springer, pp. 397-405.

Lewis, R., Schrefler, B., 1978. A fully coupled consolidation model of the subsidence of Venice. Water Resources Research 14(2), pp. 223-230.

Liu, Y., Ye, C., Jia, S., 2007. Division of water-bearing zones and compressible layers in Beijing's land subsidence areas. City Geology 2(1), pp. 10-15.

Ma, T., Zhou, C., Pei, T., Haynie, S., Fan, J., 2012. Quantitative estimation of urbanization dynamics using time series of DMSP/OLS nighttime light data: A comparative case study from China's cities. Remote Sensing of Environment 124, pp. 99-107

Pratt, W.E., Johnson, D.W., 1926. Local subsidence of the Goose Creek oil field. The Journal of Geology 34(7), pp. 577-590.

Sutton, P., Roberts, D., Elvidge, C., Baugh, K., 2001. Census from Heaven: An estimate of the global human population using night-time satellite imagery. International Journal of Remote Sensing 22(16), pp. 3061-3076.

Sutton, P.C., Elvidge, C., Obremski, T., 2003. Building and evaluating models to estimate ambient population density. Photogrammetric Engineering \& Remote Sensing 69(5), pp. 545553.

Sutton, P.C., Elvidge, C.D., Ghosh, T., 2007. Estimation of gross domestic product at sub-national scales using nighttime satellite imagery. International Journal of Ecological Economics \& Statistics 8(S07), pp. 5-21.

Tang, Y.-Q., Cui, Z.-D., Wang, J.-X., Lu, C., Yan, X.-X., 2008. Model test study of land subsidence caused by high-rise building group in Shanghai. Bulletin of Engineering Geology and the Environment 67(2), pp. 173-179.

Yan, X., Gong, S., Zeng, Z., Yu, J., Shen, G., Wang, T., 2002. Relationship between building density and land subsidence in Shanghai urban zone. Hydrogeol Eng Geol 6, pp. 21-25.

Yi, K., Tani, H., Li, Q., Zhang, J., Guo, M., Bao, Y., Wang, X., Li, J., 2014. Mapping and evaluating the urbanization process in northeast China using DMSP/OLS nighttime light data. Sensors 14(2), pp. 3207-3226.

Zhang, Y., Gong, H., Gu, Z., Wang, R., Li, X., Zhao, W., 2014. Characterization of land subsidence induced by groundwater withdrawals in the plain of Beijing city, China. Hydrogeology Journal 22(2), pp. 397-409. 
Zhao, F., Wang, Y., Yan, S., Lin, L., 2016. Reconstructing the vertical component of ground deformation from ascending ALOS and descending ENVISAT datasets-A case study in the Cangzhou area of China. Canadian Journal of Remote Sensing 42(3), pp. 147-160.

Zhu, L., Gong, H., Li, X., Wang, R., Chen, B., Dai, Z., Teatini, P., 2015. Land subsidence due to groundwater withdrawal in the northern Beijing plain, China. Engineering Geology 193, pp. 243-255.

Zhuo, L., Ichinose, T., Zheng, J., Chen, J., Shi, P., Li, X., 2009. Modelling the population density of China at the pixel level based on DMSP/OLS non-radiance-calibrated night-time light images. International Journal of Remote Sensing 30(4), pp. 1003-1018. 